\title{
Analisis Ketidakseimbangan Beban Instalasi Listrik Di Fakultas Teknik Universitas Udayana
}

\author{
Kosmas Damianus Tambi ${ }^{1}$, I N. Setiawan ${ }^{2}$, I N. Budiastra ${ }^{3}$ \\ Jurusan Teknik Elektro, Fakultas Teknik, Universitas Udayana Denpasar - Bali \\ Email : damianus elektro08@yahoo.co.id ${ }^{1}$, setiawan@e.unud.ac.id ${ }^{2},{\text { budiastra@e.unud.ac. } \mathrm{id}^{3}}^{3}$
}

\begin{abstract}
Abstrak
Beban tidak seimbang pada instalasi listrik selalu terjadi dan penyebab beban tidak seimbang dipengaruhi oleh banyak factor diantaranya pembagian beban antara fasa (fasa $R$,fasa $S$,dan fasa $T$ ) yang tidak seimbang. Akibat pembagian beban yang tidak seimbang pada masing-masing fasa tersebut mengalir arus di netral pada fasa N. Akibat arus yang mengalir di fasa netral ini menyebabkan terjadinya losses (rugi-rugi). Penelitian ini dilakukan dengan mengitung rugi-rugi daya beban seimbang dan beban tidak seimbang pada waktu malam hari di kampus Fakultas Teknik Universitas Udayana Jalan PB.Sudirman Denpasar. Berdasarkan hasil perhitungan adanya beban tidak seimbangan beban antara fasa pada MDP1 dan MDP2 telah menyebabkan terjadinya rugi-rugi daya. Besar rugi-rugi daya beban seimbang pada MDP1 sebesar 0,042 kW, dan beban tidak seimbang sebesar 0,055 kW. Sedangkan rugi-rugi untuk beban seimbang MDP2 sebesar 0,28 kW, dan beban tidak seimbang MDP2 sebesar 0,35 kW. Jadi semakin besar beban tidak seimbang yang mengalir beban pada suatu instalasi listrik, maka arus yang mengalir pada fasa netral juga besar, dan losses akibat arus netral yang mengalir ke tanah semakin besar pula.
\end{abstract}

Kata kunci: ketidakseimbangan beban,rugi-rugi daya

\begin{abstract}
The imbalance load on the electrical installation systems always the case and the cause of these imbalances is a burden sharing between phases ( $r$ phase, $s$ phase, and t phase) that is not balanced. As a result of imbalance in the load current it flows in the neutral phase of $n$. The current flowing in the neutral, causing losses. This research was conducted by analyzing the power loss in the balanced and unbalanced state at night on the campus of a University of UdayanaFaculty of Engineering on Jalan P.B. Sudirman. Based on the results of the analysis on load imbalance between phases at MDP1 and MDP2 has caused the power loss. Large power loss load balanced on MDP1 was 0,042 kW, and the unbalanced load of $0.055 \mathrm{~kW}$. While the loss of load balanced of mdp2 was $0.28 \mathrm{~kW}$, and the unbalanced load ofMDP2 was $0,35 \mathrm{~kW}$. So the greater the imbalance load on an electrical installation, the greater the neutral current, and losses due to neutral current to ground was also greater.
\end{abstract}

Keywords:Ioad imbalance, power losses

\section{PENDAHULUAN}

Listrik adalah salah satu faktor penting dalam setiap kegiatan sehari-hari. Listrik sudah menjadi kebutuhan pokok sehingga segala aktifitas manusia tidak bisa terlepas dari manfaat listrik. Dari tahun ketahun pembangunan sarana dan prasarana yang dilakukan oleh Fakultas Teknik Universitas Udayana baik dikampus Bukit Jimbaran maupun Kampus Fakultas Teknik di Jalan PB. Sudirman Denpasar secara terus menerus dilaksanakan. Pembangunan ter- sebut dimaksudkan dalam rangka menjadikan Fakultas Teknik sebagai lembaga pendidikan yang dapat melaksanakan Tri Dharma Perguruan Tinggi yang berkualitas, mendukung pembangunan yang berkelanjutan dan mampu bersaing secara global.

Tempat kegiatan yang tidak terlepas dari pemakaian energi listrik adalah ruang administrasi, ruang perpustakaan, ruang kuliah, dan studio arsitektur. Semakin bertambahnya jumlah ruangan dan semakin tinggi pemakainan listrik seperti lampu pada 
ruangan, pendingin ruangan $(A C)$, dan peralatan penunjang lainnya pada studio arsitektur, mengakibatkan meningkatnya pemakaian energi listrik yang mengalir pada instalasi listrik. Pemakaian energi listrik yang tidak merata pada jaringan instalasi listrik, menyebabkan beban tidak seimbangan disetiap fasanya dan banyaknya beban satu fasa yang beroperasi pada jam yang berbeda mengakibatkan pemakaian listrik yang tidak merata. Beberapa penelitian yang pernah dilakukan tentang beban tidak seimbang merupakan salah satu faktor yang mengakibatkan rugi-rugi daya pada saluran instalasi listrik [1].

Dari penelitian ini diperlukan analisis secara menyeluruh untuk mengetahui pengaruh dari ketidakseimbangan beban instalasi listrik di Fakultas Teknik Universitas Udayana

\section{TINJAUAN PUSTAKA}

\subsection{Sistem Tenaga Listrik}

Sistem tenaga listrik pada dasarnya dikelompokan atas tiga bagian berikut [2]:

1. Sistem Pembangkit

2. Sistem Transmisi

3. Sistem Distribusi

\subsection{Instalasi Listrik}

Adapun prinsip dasar instalasi listrik yang harus menjadi pertimbangan pada pemasangan suatu instalasi [3]. Tujuannya adalah agar instalasi yang dipasang dapat digunakan secara optimal. Adapun prinsip dasar yang dikemukakan adalah sebagai berikut.

1. Keandalan.

2. Ketercapaian.

3. Keamanan.

4. Ekonomis.

5. Keindahan

\subsection{Saluran Penghantar}

Panel Hubung Bagi (PHB) utama konsumen tenaga listrik dari PLN diterima pada bagian saluran utama konsumen dan di distribusikan melalui sirkit akhir pada masing-masing titik beban atau melalui sirkit cabang ke PHB cabang lain. Kabel NYM atau NYA pada pipa instalasi digunakan sebagai saluran penghantar pada sirkit akhir dan sirkit cabang, supaya tidak tampa pipa istalasi dari kabel NYM atau NYA ditanam dibawah permukaan dinding [4]. Penyaluran diatas plafon dapat dilaksanakan dengan cara:
1. Kebel rumah NYA di atas rol isolator.

2. Kabel rumah NYA dalam pipa

3. Kabel NYM berinti 2,3 atau 4.

4. Kabel NYY berinti 2,3 atau 4

\subsection{Arus Netral}

Arus netral pada saluran instalasi listrik merupakan arus yang mengalir pada kawat netral tiga fasa empat kawat [5]. Arus netral ini muncul jika:

1. Pada kondisi beban tidak seimbang

2. Adanya arus harmonis akibat beban non-linier.

Arus yang mengalir pada kawat netral merupakan arus bolak balik untuk saluran istalasi listrik tiga fasa empat kawat merupakan penjumlahan faktor dari ketiga arus fasa dalam komponen simetris.

\subsection{Arus Beban Penuh}

Jika dilihat dari sisi tegangan tinggi (primer), maka besarnya daya dapat dinyatakan dengan persamaan berikut.

$$
S=\sqrt{3} \cdot V \cdot I
$$

Keterangan:

$S$ adalah daya (kVA)

$\checkmark$ adalah tegangan sisi primer $(\mathrm{kV})$

I adalah arus jala-jala (A)

Untuk menghitung besarnya arus beban penuh (full load) dapat digunakan dengan persamaan sebagai berikut.

$$
I_{F L}=\frac{S}{\sqrt{3} x V}
$$

Keterangan:

IFL adalah arus beban penuh (A)

$S$ adalah transformator ( $\mathrm{KVA}$ )

$\checkmark$ adalah tegangan sisi sekunder trafo $(\mathrm{kV})$

$$
I_{\text {rata-rata }}=\frac{I_{R+} I_{S+} I_{T}}{3}
$$

Keterangan:

$I_{\text {rata-rata }}$ adalah arus ketiga fasa (A)

$I_{R}$ adalah arus fasa $\mathrm{R}(\mathrm{A})$

$I_{S}$ adalah arus fasa $S(A)$

$I_{T}$ adalah arus fasa $\mathrm{T}(\mathrm{A})$

\subsection{Keadaan seimbang dan tidak se- imbang}


Yang dimaksud dengan keadaan seimbang adalah keadaan dimana :

1. Ketiga faktor arus/tegangan sama mempunyai besaran yang sama.

2. Pada ketiga faktor saling membentuk sudut 120 satu sama lain.

Sedangkan yang dimaksud dengan keadaan beban tidak seimbang dimana salah satu atau kedua syarat beban seimbang tidak dapat terpenuhi. penyebab keadaan tidak seimbang ada tiga yaitu

1. Ketiga faktor sama besar tapi membentuk sudut $120^{\circ}$ satu sama lain

2. Ketiga faktor tidak sama besar tetapi membentuk sudut $120^{\circ}$ satu sama lain

3. Ketiga faktor tidak sama besar dan tidak membentuk sudut $120^{\circ}$ satu sama lain

\subsection{Penyaluran dan Rugi-Rugi Daya}

Daya sebesar P di distribusikan pada suatu saluran menggunakan penghantar netral. Pendistribusian daya ini, arus fasa dalam kondisi seimbang. Sehingga dapat dinyatakan besarnya daya dengan persamaan berikut [7]:

$$
P=3 . V . I . \cos \varphi
$$

Keterangan:

$P$ adalah daya pada ujung kirim ( Watt)

$V$ adalah tegangan pada ujung kirim

(V)

I adalah arus pada ujung kirim (A)

$\operatorname{Cos} \varphi$ adalah faktor daya

Faktor daya ketiga fasa dianggap sama meskipun besar arus berbeda, distribusi besarnya daya yang dinyatakan dengan persamaan sebagai berikut.

$$
P=(a+b+c) \cdot[v] \cdot[I] \cdot \cos \varphi
$$

Pada penyaluran daya dengan keadaan tidak seimbang, besarnya arus tiap fasa dapat dinyatakan dengan koefisien $a, b$, dan $c$ sebagai berikut.

$$
\begin{aligned}
& {\left[I_{R}\right]=a[I]} \\
& {\left[I_{S}\right]=a[I]} \\
& {\left[I_{T}\right]=a[I]}
\end{aligned}
$$

Arus $I_{R}, I_{S}$, dan $I_{T}$ berturut-turut adalah arus difasa $R, S$, danT.

Koefisien $a, b$,dan $c$ dapat diketahui besaranya, dimana besarnya arus fasa dalam keadaan seimbang (I) sama dengan besarnya arus rata-rata ( $\left.I_{\text {rata-rata }}\right)$.

$$
\begin{aligned}
& I_{R}=a . I_{\text {rata-rata }} \text { maka: } a=\frac{I_{R}}{I_{\text {rata-rata }}} \\
& I_{S}=a . I_{\text {rata-rata }} \text { maka: } b=\frac{I_{S}}{I_{\text {rata-rata }}} \\
& I_{T}=a . I_{\text {rata-rata }} \text { maka: } c=\frac{I_{T}}{I_{\text {rata-rata }}}
\end{aligned}
$$

Pada keadaan seimbang, nilai $a=b=c=1$.

Dengan demikian,rata- rata ketidakseimbangan beban (dalam\%) adalah:

$$
\frac{\{|a-1|+|b-1|+|c-1|\}}{3} 100 \%
$$

Prosentase pembebanan transformator dinyatakan dengan persamaan sebagai berikut.

$$
\frac{I_{\text {Rata-rata }}}{I_{F L}} \times 100 \%
$$

Keterangan:

$$
I_{\text {rata-rata }} \text { adalah arus ketiga fasa (A) }
$$$$
I_{F L} \quad \text { adalah arus beban penuh (A) }
$$

\subsection{Rugi-Rugi Daya Pada Instalasi Litrik}

Besarnya daya yang hilang pada suatu jaringan disebut Rugi-rugi daya, dan besarnya rugi-rugi daya satu fasa dapat dinyatakan dengan persamaan sebagai berikut.

$$
\Delta P=I^{2} \cdot R
$$

Keterangan:

$\triangle P$ adalah rugi -rugi daya (watt)

$I$ adalah arus beban pada jaringan (A)

$R \quad$ adalah tahanan murni $(\Omega)$

Besarnya rugi-rugi daya pada jaringan tergantung besarnya tahanan dan arus beban pada jaringan tersebut. Untuk mengetahui besarnya rugi daya pada jaringan tiga fasa dapat dinyatakan dengan persamaan sebagai berikut.

$$
\Delta P=3 . I^{2}
$$

\subsection{Rugi-Rugi Daya Akibat Ketidak- seimbangan Beban}

Akibat dari beban tidak seimbang disetiap fasa pada sisi sekunder transformator (phase R, phase S, phaseT) dapat mengalirl arus dinetral trafo. Arus yang mengalir pada penghantar netral trafo ini mengakibatkan losses (rugi-rugi). Losses 
pada penghantar netral trafo dapat dinyatakan dengan persamaan sebagai berikut.

$$
P_{N}=I_{N}^{2} \cdot R_{N}
$$

Keterangan:

$P_{N} \quad$ adalah losses pada penghantar netral (Watt)

$I_{N} \quad$ adalah arus yang mengalir pada netral (A)

$R_{N}$ adalah tahanan penghantar netral $(\Omega)$

Sehingga daya aktif dapat dihitung dengan persamaan sebagai berikut .

$$
P=S \cdot \cos \varphi
$$

Keterangan:

$P \quad$ adalah daya aktif (watt)

$S \quad$ adalah daya semu (watt)

$\cos \varphi$ adalah 0,85

Sehingga prosentase rugi-rugi daya akibat adanya arus netral dan efisiensi pada penghantar netral adalah :

$$
\begin{aligned}
& \% P_{N}=\frac{P_{N}}{P} \times 100 \% \\
& \eta=\frac{P_{\text {out }}}{P_{\text {in }}} \times 100 \%
\end{aligned}
$$

Keterangan :

$P_{N}$ adalah rugi-rugi daya pada penghantar netral(Watt)

$P$ adalah daya aktif(Watt)

\section{METODE PENELITIAN}

Penelitian ini megunakan data primer yang bersumber dari pengukuran langsung pada Fakultas Teknik Universitas Udayana serta beberapa data sekunder yang didapat dari refrensi buku-buku yang berkaitan dengan analisis beban tidak seimbang terhadap arus netral dan losses.

Berikut adalah tahapan analisis:

1. Pengumpulan data pada masingmasing MDP.

2. Analisis aliran daya dengan beban seimbang dan beban tidak seimbang masing-masing MDP

3. Menghitung rugi-rugi daya pada masing-masing SDP pada kondisi beban seimbang dan kondisi beban tidak seimbang.

\section{HASIL DAN PEMBAHASAN}

\subsection{Tinjauan Umum Sistem Kelistrikan Fakultas Teknik Universitas Udayana Denpasar}

Kampus Fakultas Teknik Universitas Udayana Denpasar memiliki 6(enam) Gedung yaitu: Gedung Administrasi, Gedung $A, B, C, D, E$,dan ruang Perpustakaan. untuk memenuhi kebutuhan energi listrik, Fakultas Teknik Universitas Udayana Denpasar menggunakan sumber energi listrik utama yang disuplai dari PLN dan memiliki daya yang tersambung masing-masing MDP 33 kVA dan 66 kVA. MDP1 terletak pada ruang administrasi, MDP2 terletak pada GedungC lantai 1.

\subsection{Data Sistem Kelistrikan di Kampus Fakultas Teknik}

Secara garis besar sistem kelistrikan di Fakultas Teknik Udayana terdiri dari dua Main Distribution Panel (MDP) yang terbagi lagi menjadi (3) Sub Distribution Panel (SDP) pada MDP1 dan (12) Sub Distribution Panel (SDP) pada MDP2. Diagram garis tunggal sistem kelistrikan di Fakultas Teknik Udayana dapat dilihat pada gambar 4.1 dan gambar 4.2.

Data untuk analisa pembahasan studi pengaruh ketidak seimbangan beban diFa-kultas Teknik Udayana. antara lain:

1. Data pembebanandi masing-masing MDP

2. Data pengukuran arus pada tiap fasa ( $R, S$ dan $T$ )

3. Data panjang penghantar dan diameter jenis penghantar yang dipakai pada sistem kelistrikan Fakultas Teknik Universitas Udayana.

\subsection{Tabel Pengukuran Pada kWH 1 Ruang Administrasi}

Tabel 1. Pengukuran malam hari MDP1Ruang Administrasi

\begin{tabular}{|c|c|c|c|c|c|}
\hline \multirow{2}{*}{ hari } & \multirow{2}{*}{ Jam } & \multicolumn{4}{|c|}{ Arus (A) } \\
\cline { 3 - 6 } & $\mathbf{R}$ & $\mathbf{S}$ & $\mathbf{T}$ & $\mathbf{N}$ \\
\hline Senin & 19,30 & 48 & 12,5 & 33,2 & 19,5 \\
\hline Selasa & 19,30 & 38,8 & 29,9 & 26 & 15,4 \\
\hline Rabu & 19,30 & 36 & 20 & 25 & 12,4 \\
\hline Kamis & 19,30 & 38 & 21 & 24 & 16,5 \\
\hline Jumat & 19,30 & 30 & 21 & 24 & 12,5 \\
\hline
\end{tabular}

Tabel 2. Pengukuran malam hari MDP2 Gedung

\begin{tabular}{|c|c|c|c|c|c|}
\hline \multirow{2}{*}{ hari } & \multirow{2}{*}{ Jam } & \multicolumn{4}{|c|}{ Arus (A) } \\
\cline { 3 - 6 } & & $\mathbf{R}$ & S & T & N \\
\hline Senin & 19,00 & 130 & 62 & 89 & 52 \\
\hline Selasa & 19,00 & 90 & 57 & 64 & 29 \\
\hline Rabu & 19,00 & 111 & 67 & 80 & 35 \\
\hline Kamis & 19,00 & 114 & 69 & 60 & 42 \\
\hline Jumat & 19,00 & 107 & 65 & 91 & 28 \\
\hline
\end{tabular}



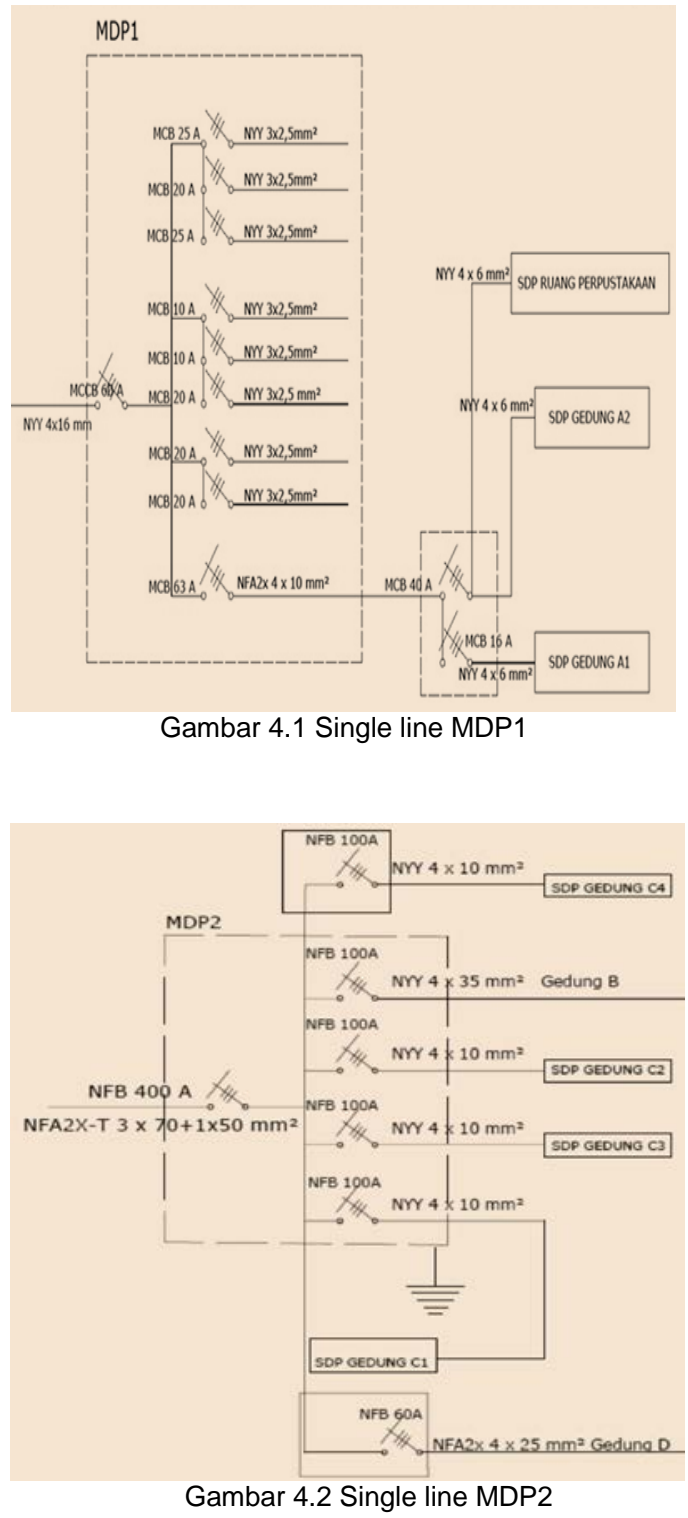

\subsection{Prosentase Pembeban MDP1}

Menghitung nilai pembebanan arus beban penuh menggunakan Persamaan (2) dengan perhitungan sebagai berikut.

$$
\text { Kapasiatas kW = } 33 \text { kVA }
$$$$
\text { Tegangan }=380 \mathrm{~V}
$$

$$
I_{F L}=\frac{S}{\sqrt{3} x V}=\frac{33.000}{\sqrt{3.380}}=50,15 \mathrm{~A}
$$

Hasil perhitungan nilairata-rata MDP1 ketigafasa menggunakan Persamaan(3) dengan hasil perhitungan sebagai berikut.

$$
\begin{gathered}
I_{\text {Rata-rata }}=\frac{I_{R}+I_{S}+I_{T}}{3}=\frac{48+12,5+33,2}{3} \\
=31,23 \mathrm{~A}
\end{gathered}
$$

Prosentase pembebanan MDP1 menggunakan Persamaan (7) dengan hasil perhitungan sebagai berikut.

$$
\begin{gathered}
\frac{I_{\text {Rata-rata }}}{I_{F L}} \times 100 \%=\frac{31,23}{50,15} \times 100 \\
=62,27 \%
\end{gathered}
$$

Hasil yang di peroleh menunjukan bahwa beban puncak MDP1 terjadi malam hari sebesar $62,27 \%$. Terjadinya selisih prosentase pembebanan ini disebabkan karena pemakaian energi listrik lebih besar terjadi pada malam hari.

\subsection{Prosentase Pembebanan MDP2}

Menghitung nilai pembebanan arus beban penuh menggunakan Persamaan (2) dengan perhitungan sebagai berikut.

$$
I_{F L}=\frac{S}{\sqrt{3} \times V}=\frac{66000}{\sqrt{3} \times 380}=100,30 \mathrm{~A}
$$

Menghitung nilai rata-rata ketiga fasa menggunakan Persamaan (3) dengan perhitungan sebagai berikut.

$$
\begin{gathered}
I_{\text {Rata-rata }}=\frac{I_{R}+I_{S}+I_{T}}{3}=\frac{130+62+89}{3} \\
=93,66 \mathrm{~A}
\end{gathered}
$$

Prosentase pembebanan MDP2menggunakan Persamaan(7) dengan hasil perhitungan sebagai berikut.

$$
\begin{gathered}
\frac{I_{\text {Rata-rata }}}{I_{F L}} \times 100 \%=\frac{93,66}{100,30} \times 100 \% \\
=93,37 \%
\end{gathered}
$$

\subsection{Prosentase Ketidakseimbangan Beban Masing-masing MDP}

Perhitungan ketidakseimbangan beban dilakukan pada malam hari pada MDP1 dengan Persamaan (3), (4), (5). dan untuk mencari nilai koefisiensi $a, b$, dan $c$ dengan hasil perhitungan sebagai berikut.

$$
\begin{aligned}
& a=\frac{I_{R}}{I_{\text {Rata-rata }}}=\frac{48}{31,56}=1,5 \\
& b=\frac{I_{S}}{I_{\text {Rata-rata }}}=\frac{12.5}{31,56}=0,3 \\
& c=\frac{I_{T}}{I_{\text {Rata }- \text { rata }}}=\frac{33,2}{31,56}=1,0
\end{aligned}
$$


Dari hasil yang diperoleh menunjukan bahwa prosentase ketidak-seimbangan beban MDP1 sebesar:

$$
\begin{aligned}
& =\frac{\{[a-1]+[b-1]+[c-1]\}}{3} \chi 100 \\
& =\frac{\{[1,5-1]+[0,3-1]+[1,0-1]\}}{3} \times 100 \\
& =\frac{\{[0,5]+[-0,7]+[0]\}}{3} \chi 100 \\
& =40 \%
\end{aligned}
$$

Dengan perhitungan yang sama dapat dianalisis untuk MDP2 dengan perhitungan sebagai berikut.

$$
\begin{aligned}
& a=\frac{I_{R}}{I_{\text {Rata-rata }}}=\frac{130}{84,46}=1,5 \\
& b=\frac{I_{S}}{I_{\text {Rata-rata }}}=\frac{62}{84,46}=0,7 \\
& c=\frac{I_{T}}{I_{\text {Rata }- \text { rata }}}=\frac{89}{84,46}=1,0
\end{aligned}
$$

Berdasarkan hasil perhitungan yang didapat diketahui prosentase beban tidak seimbang MDP2 sebesar:

$$
\begin{aligned}
& =\frac{\{[a-1]+[b-1]+[c-1]\}}{3} \times 100 \% \\
& =\frac{\{[1,5-1]+[0,7-1]+[1,0-1]\}}{3} \times 100 \\
& =\frac{\{[0,5]+[0,3]+[0]}{3} \times 100 \%=26 \%
\end{aligned}
$$

\subsection{Analisis Kondisi Beban Seimbang SDP MDP1 dan MDP2}

Perhitungan rugi-rugi daya pada beban penghantar NYY $4 \times 10 \mathrm{~mm}^{2}$ dengan menggunakan Persamaan(8) dengan hasil perhitungan sebagai berikut.

$$
\begin{aligned}
& I_{\text {rata-rata }}=5,36 \mathrm{~A} \\
& \begin{aligned}
L & =15 \text { meter }=0,015 \mathrm{~km} \\
R & =3,0 \text { Ohm } / . \mathrm{km} \\
& =3,0.0,015 \\
& =0,045 \mathrm{ohm}
\end{aligned}
\end{aligned}
$$

Menggunakan Persamaan (22) hasil perhitungan sebagai berikut.

$$
\Delta P=3 \cdot I^{2} \cdot R
$$

$$
\begin{aligned}
& =3.5,36^{2} \cdot 0,045 \\
& =3,878 \text { Watt }
\end{aligned}
$$

Hasil perhitungan total rugi-rugi daya ketidakseimbangan beban pada SDP ruangperpustakaan sebesar 3,878 Watt.

Hasil perhitungan yang sama dapat di hitung pada masing-masing SDP yang memiliki arus beban yang berbeda serta panjang penghantar yang berbeda-beda.

Tabel 3.Rugi-rugi daya pada MDP1

\begin{tabular}{|c|c|c|}
\hline Uraian & $\begin{array}{c}\text { Panjang } \\
\text { Penghantar } \\
\text { (Meter) }\end{array}$ & $\begin{array}{c}\text { Total } \\
\text { Rugi-Rugi } \\
\text { Daya(Watt) }\end{array}$ \\
\hline $\begin{array}{c}\text { Ruang } \\
\text { Perpustakaan }\end{array}$ & 20 & 3,878 \\
\hline SDP.A & 25 & 42,688 \\
\hline \multicolumn{2}{|c|}{ Total } & 46,566 \\
\hline
\end{tabular}

Tabel 4.Rugi-rugi daya pada MDP2

\begin{tabular}{|c|c|c|}
\hline Uraian & $\begin{array}{c}\text { Panjang } \\
\text { Pengahantar (Meter) }\end{array}$ & $\begin{array}{c}\text { Total Rugi-rugi } \\
\text { Daya (Watt) }\end{array}$ \\
\hline SDPB1 & 5 & 0,204 \\
\hline SDPB2 & 5 & 1,774 \\
\hline SDPB3 & 15 & 7,117 \\
\hline SDPB4 & 20 & 17,596 \\
\hline SDPC1 & 2 & 1,403 \\
\hline SDPC2 & 10 & 7,350 \\
\hline SDPC3 & 15 & 18,610 \\
\hline SDP Gedung D & 50 & 204,788 \\
\hline SDPD2 & 5 & 0,895 \\
\hline SDPD3 & 15 & 18,989 \\
\hline SDP Ruang E & 10 & 7,834 \\
\hline Total & & 286,56 \\
\hline
\end{tabular}

4.8 Analisis pada Kondisi Beban Tidak Seimbang masing - masing SDP MD1 dan MDP2

Menghitung rugi-rugi daya tidak seimbang pada SDP Ruang Perpustakaan digunakan persamaan yang sama dengan cara perhitungan sebagai berikut.

Rugi daya untuk SDP ruang perpustakaan dengan penghantar NYY $4 \times 10 \mathrm{~mm}^{2}$

$$
\begin{aligned}
I_{R} & =10,2 \mathrm{~A} \\
I s & =5,3 \mathrm{~A} \\
I_{T} & =0,6 \mathrm{~A} \\
L & =15 \text { meter }=0,015 \mathrm{~km} \\
R & =3,0 \text { Ohm } / \mathrm{km} \\
& =3,0 \cdot 0,015=0,045 \mathrm{ohm}
\end{aligned}
$$


Menggunakan Persamaan (8) hasil perhitungan sebagai berikut.

$$
\begin{aligned}
I_{\mathrm{R}} & =10,2 \mathrm{~A} \\
\Delta P & =I_{R}{ }^{2} \cdot R \\
& =10,2^{2} \cdot 0,045 \\
& =4,681 \text { Wat } \\
I_{S} & =5,3 \mathrm{~A} \\
\Delta P & =I_{S}^{2} \cdot R \\
& =5,3^{2} \cdot 0,045 \\
& =1,264 \text { Watt } \\
I_{T} & =0,6 \mathrm{~A} \\
\Delta P & =I_{T}^{2} \cdot R \\
& =0,6^{2} \cdot 0,045 \\
& =0,016 \text { Watt }
\end{aligned}
$$

Dari perhitungan diketahui total rugirugi pada saluran SDP ruang perpustakaan sebesar:

$$
\begin{aligned}
\Delta P_{R}+\Delta P_{S}+\Delta P_{T} & =4,681+1,264+0,016 \\
& =5,961 \mathrm{Watt} .
\end{aligned}
$$

Hasil perhitungan yang sama dapat dihitung pada masing-masing SDP yang memiliki arus beban yang berbeda serta panjang penghantar yang berbeda-beda.

Tabel 5.Total rugi-rugi daya beban tidak seimbang MDP2

\begin{tabular}{|c|c|c|c|c|}
\hline Uraian & $\mathbf{R}$ & $\mathbf{S}$ & $\mathbf{T}$ & $\begin{array}{c}\text { Total } \\
\text { Rugi-rugi Daya (Watt) }\end{array}$ \\
\hline SDPB1 & 0 & 0,001 & 0,558 & 0,559 \\
\hline SDPB2 & 1,323 & 0,311 & 1,332 & 2,975 \\
\hline SDPB3 & 1,894 & 9,897 & 0,009 & 11,8 \\
\hline SDPB4 & 30,524 & 0 & 2,647 & 3,171 \\
\hline SDPC1 & 0,905 & 1,022 & 0,008 & 1,935 \\
\hline SDPC2 & 1,719 & 1,862 & 4,081 & 7,661 \\
\hline SDPC3 & 14,451 & 7,578 & 0,842 & 22,871 \\
\hline SDP Gedung 0 & 60,733 & 16,733 & 166,637 & 244,044 \\
\hline SDPD2 & 0,109 & 0,172 & 1,083 & 1,264 \\
\hline SDPD3 & 3,175 & 2,668 & 17 & 22,954 \\
\hline SDP Ruang E & 2,881 & 2,650 & 2,323 & 7,853 \\
\hline Total & & & & $\mathbf{3 5 7 , 0 8 7}$ \\
\hline
\end{tabular}

Tabel 6.Total rugi-rugi daya beban tidak seimbang

MDP1
\begin{tabular}{|c|c|c|c|c|}
\hline Uraian & $\mathbf{R}$ & $\mathbf{S}$ & $\mathbf{T}$ & $\begin{array}{c}\text { Total Rugi-rugi } \\
\text { Daya (Watt) }\end{array}$ \\
\hline $\begin{array}{c}\text { Ruang } \\
\text { Perpustakaan }\end{array}$ & 4,681 & 1,264 & 0,016 & 5,961 \\
\hline $\begin{array}{c}\text { SDP A1 } \\
\text { Ruang Admin }\end{array}$ & 15,941 & 3,110 & 30,917 & 49,968 \\
\hline Total & & & 55,929 \\
\hline
\end{tabular}

\subsection{Hasil Perbandingan Rugi-rugi Daya}

Berikut ini adalah hasil berbandingan pada masing-masing MDP.

Tabel 7. PerbandinganRugi-rugi Daya pada masingmasing SDP

\begin{tabular}{|c|c|c|c|}
\hline \multicolumn{2}{|c|}{ Beban } & $\begin{array}{c}\text { Total Rugi-rugi } \\
\text { Daya (Waa) }\end{array}$ & $\begin{array}{c}\text { Total Rugi-rugi } \\
\text { Daya (KW) }\end{array}$ \\
\hline \multirow{2}{*}{ Seimbang } & MDP1 & 42,688 & 0,042 \\
\cline { 2 - 4 } & MDP2 & 286,56 & 0,28 \\
\hline
\end{tabular}

\section{KESIMPULAN}

Beberapa hal dapat disimpulkan dari penelitian ini adalah sebagai berikut.

1. Instalasi listrik di kampus Fakultas Teknik Universitas Udayana dalam keadaan tidak seimbang karena arus yang mengalir di masing-masing fasa berbeda.

2. Ketidak seimbangan beban lebih besar terjadi pada malam hari. Persentase ketidakseimbangan beban pada malam hari sebesar $40 \%$ pada MDP1 dan 26\% pada MDP2.

\section{DAFTAR PUSTAKA}

[1] Setiadji,2006. Pengaruh Ketidakseimbangan Beban Terhadap Arus Netral Dan Losses Pada Trafo Distribusi. Jurnal Teknik Elektro, Volume 6, No. 1.

[2] Zuhal, Dasar Tenaga listrik. Bandung: ITB 1982

[3] Muhaimin.2001.Teknologi

Pencahayaan, Refika Aditama, Malang.

[4] Sugandi, L , dkk , 2001 , Panduan Instalasi Listrik untuk Rumah. Jakarta :Yayasan Usaha Penunjang Tenaga Listrik

[5] Standar Nasional Indonesia (SNI). Persyaratan Umum Instalasi Listrik 2012 (PUIL 2011) SNI 04-02252000.Jakarta. Yayasan PUIL

[6] Kusuma ,Widya, 2009. Analisis RugiRugi Daya Akibat Ketidakseimbangan Beban. Jimbaran : Program Studi Teknik Elektro Universitas Udayana.

[7] Harten, PV, Terjemahan Setiawan E. 2001. Instalasi Listrik Arus Kuat 1. Bandung: Binacipta

[8] Sentosa,dkk. 2006, "Pengaruh Ketidakseimbangan Beban Terhadap Arus Netral dan Losses pada Trafo Distribusi", PT. PLN (persero), Surabaya, 